\title{
Commentary: Go "all in" the way they do in Texas-Or wait to see how the hand plays out? Extent of distal repair for acute type I dissection
}

\author{
Charles M. Wojnarski, MD, MS, and G. Chad Hughes, MD
}

\author{
From the Division of Cardiovascular and Thoracic Surgery, Department of Surgery, Duke University Medical \\ Center, Duke University, Durham, NC. \\ Disclosures: Authors have nothing to disclose with regard to commercial support. \\ Received for publication Jan 13, 2019; accepted for publication Jan 14, 2019; available ahead of print March 4, \\ 2019. \\ Address for reprints: Charles M. Wojnarski, MD, MS, Duke University Medical Center, 2301 Erwin Rd, Durham, \\ NC 27710 (E-mail: charles.wojnarski@duke.edu). \\ J Thorac Cardiovasc Surg 2019;158:1283-4 \\ $0022-5223 / \$ 36.00$ \\ Copyright (c) 2019 by The American Association for Thoracic Surgery \\ https://doi.org/10.1016/j.jtcvs.2019.01.051
}

In this issue of the Journal, Preventza and colleagues ${ }^{1}$ present a consecutive series of 178 patients on whom acute type I aortic dissection repair was performed at a single institution from 2005 to 2016 . They compare the perioperative outcomes and 5-year follow-up data of patients who underwent standard open ascending aortic replacement (with or without valve, root, or arch replacement) with those of patients who underwent standard repair with the addition of antegrade deployment of a descending aortic stent graft. They use propensity score matching in an attempt to adjust for differences in patient-level characteristics between groups. During the decade-long experience, Preventza and colleagues ${ }^{1}$ describe an evolving set of indications for adding descending aortic stent grafting at the time of initial repair. At the outset, descending aortic stent grafting was added only in patients with abdominal or peripheral malperfusion, whereas indications were more prophylactic by the end of the study period.

Three main perioperative outcomes are presented: operative mortality, stroke, and spinal cord ischemia. In both unmatched and propensity score-matched comparisons, there were no statistically significant differences in outcome by group. After matching, the difference in operative mortality between groups approached statistical significance (stent, $13.0 \%$ vs no stent, $30.4 \% ; P=.059)$. Survival at 5 years favored the stent-first approach (stent, $66.3 \%$ vs no stent, $41.6 \%, P=.015$ ), with most of the survival difference occurring in the acute phase within 6 months of operation, followed by relatively parallel curves thereafter.

The purpose of propensity score matching in any observational study is to mimic for retrospective data the balancing effect of prospective randomization on prospective data. ${ }^{2}$ Propensity score matching allows one to estimate a population average for treatment effects and present indirectly "covariate-adjusted" differences between treatments. A simple way of describing this phenomenon is to

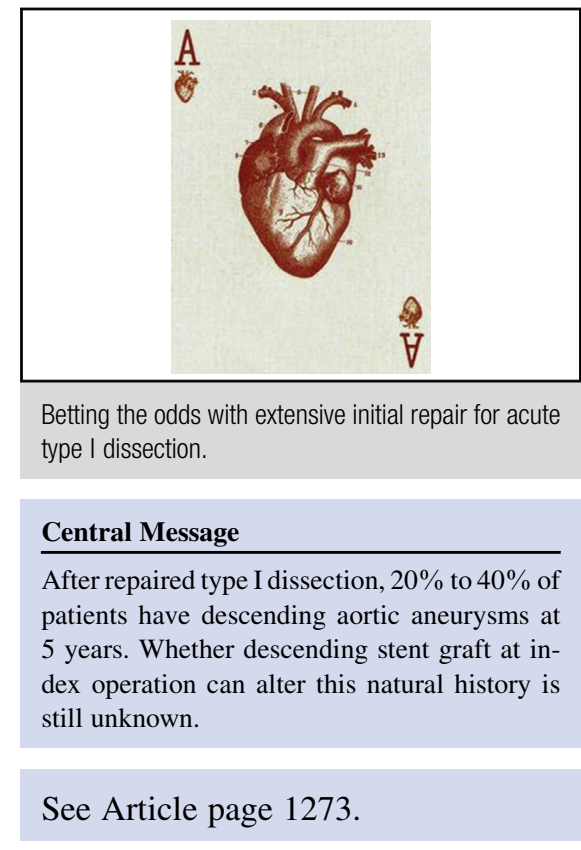

say that propensity score matching allows one to take 2 groups that have somewhat similar characteristics and make them almost "equivalent." Where investigators often run into trouble is in attempting to compare groups that are very different from each other. This can be accomplished with large sample sizes, but propensity score matching of small populations (40-60 patients) runs a significant risk of type I error. ${ }^{3}$ One thus should be very cautious with the interpretation of treatment effects with large differences before matching, small sample sizes, and low outcome prevalence. Indeed, our comprehensive reading of this article left us with more questions than answers.

First, and most importantly, the differences in survival found in this study are more likely to be due to unresolved selection bias than to arise from the short-term benefits of a 10 - to $20-\mathrm{cm}$ proximal descending aortic stent graft. Second, malperfusion from aortic dissection is a critical concept that should be characterized by a validated systematic classification. ${ }^{4}$ One cannot lump cerebral, coronary, and mesenteric ischemia in with kidney or extremity malperfusion, as was done in the study of Preventza and colleagues, ${ }^{1}$ because each has a profoundly different effect on perioperative outcomes. The finding that spinal cord ischemia rates were not statistically higher with the stent- 
graft strategy may have been a function of small sample size. Finally, aortic remodeling refers to either a decrease in aortic diameter or stability of aortic diameter with false-lumen regression and expansion of the true lumen. ${ }^{5}$ This outcome, rather than the surrogate of false-lumen thrombosis, as used by Preventza and colleagues, ${ }^{1}$ is of critical interest as an indicator of late aortic risk for those following up patients for aneurysmal degeneration after aortic dissection.

Rather than focusing on the methodology and results of a small, single-institution retrospective study, however, this commentary is meant to highlight the need for a prospective, multi-institutional trial that compares overall and aorta-specific survivals in patients randomly assigned to undergo proximal aortic repair alone versus proximal repair with addition of a descending aortic stent graft. Not only would such a trial provide insights into the perioperative impact of additional intervention, but the unstented group would serve as a natural history arm-if prospectively followed up with standardized, interval imaging surveillance-for the need for future aortic intervention. All the aforementioned problems with retrospective studies aimed at answering this study question would be obviated with the proposed study design.

Two recent studies have shown that for patients who have undergone proximal repair alone for type I dissection, risk for distal reintervention at 5 years is approximately $20 \%$ to $40 \%$, with excellent perioperative outcomes, at highvolume aortic centers. ${ }^{6,7}$ Whether the potential long-term benefits of adding a descending aortic stent graft at the index operation for acute type I aortic dissection outweigh the likely additive risks can only be answered by a prospective, randomized, controlled trial. Finally, widespread adoption of branched stent graft technology for the ascending aorta and arch is very much on the near horizon. ${ }^{8,9}$ These devices may dramatically change the way that we treat type I dissection, and the questions that we find ourselves asking in the next 5 years may be quite different than the ones that we still have unanswered today.

\section{References}

1. Preventza O, Olive JK, Liao JL, Orozco-Sevilla V, Simpson K, Rodriguez MR, et al. Acute type I aortic dissection with or without antegrade stent delivery: mid-term outcomes. J Thorac Cardiovasc Surg. 2019;158:1273-81.

2. Austin PC. An introduction to propensity score methods for reducing the effects of confounding in observational studies. Multivariate Behav Res. 2011;46:399-424.

3. Pirracchio R, Resche-Rigon M, Chevret S. Evaluation of the propensity score methods for estimating marginal odds ratios in case of small sample size. BMC Med Res Methodol. 2012;12:70.

4. Augoustides JG, Szeto WY, Desai ND, Pochettino A, Cheung AT, Savino JS, et al. Classification of acute type a dissection: focus on clinical presentation and extent. Eur J Cardiothorac Surg. 2011;39:519-22.

5. Famularo M, Meyermann K, Lombardi JV. Aneurysmal degeneration of type B aortic dissections after thoracic endovascular aortic repair: a systematic review. J Vasc Surg. 2017;66:924-30.

6. Wang H, Wagner M, Benrashid E, Keenan J, Wang A, Ranney D, et al. Outcomes of reoperation after acute type A aortic dissection: implications for index repair strategy. J Am Heart Assoc. 2017;6:e066376.

7. Roselli EE, Loor G, He J, Rafael AE, Rajeswaran J, Houghtaling PL, et al. Distal aortic interventions after repair of ascending dissection: the argument for a more aggressive approach. J Thorac Cardiovasc Surg. 2015;149(2 Suppl): 117-24.e3.

8. Desai ND, Wang G, Hoedt A, Szeto W, Bavaria JE. Double transposition and single branched TEVAR for total arch replacement in chronic dissection. Ann Cardiothorac Surg. 2018;7:434-6.

9. Roselli EE, Idrees JJ, Greenberg R, Johnston DR, Lytle BW. Endovascular stent grafting for ascending aorta repair in high-risk patients. J Thorac Cardiovasc Surg. 2015;149:144-51. Erratum in: J Thorac Cardiovasc Surg. 2016;152:292. 